\title{
Genetic analysis of Toxocara spp. in stray cats and dogs in Van province, Eastern Turkey
}

\author{
Bekir Oguz, Nalan Ozdal, M. Serdar Deger \\ Department of Parasitology, Faculty of Veterinary Medicine, \\ Van Yuzuncu Yil University, 65040, Van, Turkey \\ bekiroguz@yyu.edu.tr
}

Received: March 29, $2018 \quad$ Accepted: August 27, 2018

\begin{abstract}
Introduction: Toxocara canis and Toxocara cati are roundworms of dogs and cats. The purpose of this study was to investigate the infection caused by these ascarids in cats and dogs, using microscopic and molecular analysis methods. Material and Methods: Adult ascarids were gathered from the faeces of dogs and cats in Van province, in 2015-2016. Existing keys and PCR sequencing of the ITS-2 fragment were used to identify the morphological features of the parasite species. Results: It was observed that out of 20 adult ascarids, 17 and 3 were found to be Toxocara canis and Toxocara cati, respectively. The ITS-2 gene region was amplified by PCR to perform molecular analysis. Genotyping indicated that the dogs and cats were infected with T. canis and T. cati, respectively, and none had Toxascaris leonina. Conclusion: To the best of our knowledge, this is the first report on the molecular characteristics of adult ascaridoid nematodes from cats and dogs in Turkey. The molecular approaches established in this study enable molecular identification and genetic structure studies of the ascaridoids.
\end{abstract}

Keywords: dogs, cats, Toxocara, genetic marker, Turkey.

\section{Introduction}

Toxocara canis and Toxocara cati are the most common nematodes living in the small intestine of dogs and cats. Female nematodes may produce up to 200,000 eggs per day, which require an incubation period in the soil before they are infective $(5,23)$. Therefore, contact with soil contaminated with Toxocara eggs is vital for infection to take place. In humans, toxocariasis is mainly caused by two Toxocara species, which are the dog nematode, $T$. canis and that of cats, T. cati. It is reported that $T$. canis is more frequently detected in human cases and $T$. cati is rarely seen. The most important clinical outcomes in humans are visceral larva migrans (VLM) and ocular larva migrans (OLM) due to the prolonged migration of the larvae of $T$. canis $(10,19)$. Felines are infected by T. cati, T. malaysiensis, T. leonina, and occasionally T. canis. Toxascaris leonina also causes infection in canids and felids $(4,14)$. It is not yet clear whether some of these species have caused disease in humans. Therefore, there is a need for a molecular technique to detect and identify the ascaridoid nematodes accurately (14).

Zoonotic roundworm infections are highly prevalent in many developing countries (9). It was reported that the prevalence rates of $T$. canis and $T$. cati were $4.2 \%-47.8 \%$ and $47 \%-85 \%$ in dogs and cats, respectively, in Turkey as determined microscopically $(1,26)$. The role of $T$. cati as a zoonotic parasite is not always clearly recognised. Based on epidemiological factors, most of the cases reported in human regarding toxocariasis have been associated with $T$. canis (2), although the distinction of $T$. canis infection from $T$. cati infection has not been achieved yet in serological studies. Toxocara excretory-secretory antigens (TES) shared between T. canis and T. cati and similarity in the form of infection are the findings indicating that there is no difference in risk to the public health between the two zoonotic diseases. For this reason, the potential role of $T$. cati in human toxocariasis should be paid sufficient attention (20). A study performed in the Netherlands has shown that about $50 \%$ of clinical toxocariasis cases were 
associated with simultaneous Ascaris suum and Toxocara spp. infections (25). Also in the Netherlands, Pinelli et al. (22) indicated seroepidemiological incidence of Toxocara and Ascaris among VLM/OLMsuspected patients during 11 consecutive years (1998-2009) and emphasised the potential extent of A. suum as a causative agent for VLM/OLM. The traditional methods to identify and differentiate $T$. canis, $T$. cati, and $T$. leonina are based on microscopic analysis. T. leonina and $T$. canis are very similar but can be differentiated by the cephalic alae. However, to identify this difference is very difficult because specialised and qualified staff is required for these kinds of analysis (18). Since morphological methods are incapable of distinguishing closely related species, molecular methods should be used for accurate identification. The second internal transcribed spacer (ITS-2) has been used to identify nematodes in dogs, foxes, and cats (8).

The current study performed for the identification of adult ascaridoid nematodes from dogs and cats was based on both microscopic and ITS-2 region analysis. To our knowledge, this is the first molecular characterisation of adult $T$. canis and T. cati in Turkey.

\section{Material and Methods}

Microscopic analysis. Adult ascaris worms were collected from faeces of dogs and cats in Van province, Eastern Turkey, during 2015-2016. Nematodes were first washed extensively twice in phosphate buffered saline (PBS) and then were identified by microscopy as $T$. canis or $T$. cati, according to existing keys $(12,15)$. After that, the parasites were fixed in $70 \%$ ethanol and frozen at $-20^{\circ} \mathrm{C}$ until extraction of genomic DNA.

Molecular analysis. Total genomic parasite DNA was extracted using a DNA extraction reagent kit (the GeneJET Genomic DNA Purification Kit, Thermo Scientific, USA), according to the manufacturer's recommendations. The extracts were kept at $-20^{\circ} \mathrm{C}$. For molecular diagnosis, species-specific primers were chosen from ITS2 region sequences that had previously been described as Tcan1 (5'-AGTATGATGGGCGC GCCAAT-3') and NC2 (5'-TAGTTTCTTTTCCTCC GCT-3') for T. canis, Tcat1 (5'-GGAGAAGT AAACTC-3') and NC2 for T. cati, and Tleo1 (5'-CGAACGCTCATATAACGGCATACTC-3') and NC2 for $T$. leonina (8). PCR was carried out in a final volume of $20 \mu \mathrm{L}$ containing: $7.5 \mu \mathrm{L}$ of DNase- and RNase-free sterile distilled water (Biobasic, Canada), $5 \mu \mathrm{L}$ of $5 \times$ MyTaq Reaction buffer (Bioline, USA), $1 \mu \mathrm{L}$ of each primer $(20 \mathrm{pmol}), 5 \mu \mathrm{L}$ of template DNA (100-200 ng), and $0.5 \mu \mathrm{L}$ of TaqDNA polymerase (1.25 IU) (MBI Fermentas, USA). The PCR conditions were as follows: $30 \mathrm{~s}$ at $94^{\circ} \mathrm{C}$ (initial denaturation), 35 cycles of $30 \mathrm{~s}$ at $94^{\circ} \mathrm{C}, 30 \mathrm{~s}$ at $56^{\circ} \mathrm{C}$ (T. leonina) or $58^{\circ} \mathrm{C}$ ( T. cati/T. canis), $30 \mathrm{~s}$ at $72^{\circ} \mathrm{C}$, and finally $5 \mathrm{~min}$ at $72^{\circ} \mathrm{C}$ (final extension). The PCR products were separated on agarose gels (1.5\%), stained with ethidium bromide, and visualised and photographed by a UV transilluminator. The PCR products were subjected to capillary electrophoretic separation in a specialised laboratory (Sentegen, Turkey), and sequence analyses of the products were performed. Sequence data were compared with other ascarids available at the NCBI (http://blast.ncbi.nlm.nih.gov/Blast.cgi), while alignments and phylogenetic analysis were conducted, using the software MEGA and Bioedit (12).

\section{Results}

The collected Toxocara nematodes were identified microscopically based on morphological features. The male worms had a posterior end curved ventrally, showing a considerable point at the tail-end which was distinguishable from the straight-tailed female worms (Fig. 1. A and B). Some of the samples showed a lanceshaped cephalic alae, while others revealed very broad cephalic alae (Fig. $1 \mathrm{C}$ and D). In female worms, the eggs were brownish and almost spherical (Fig. 1 E).

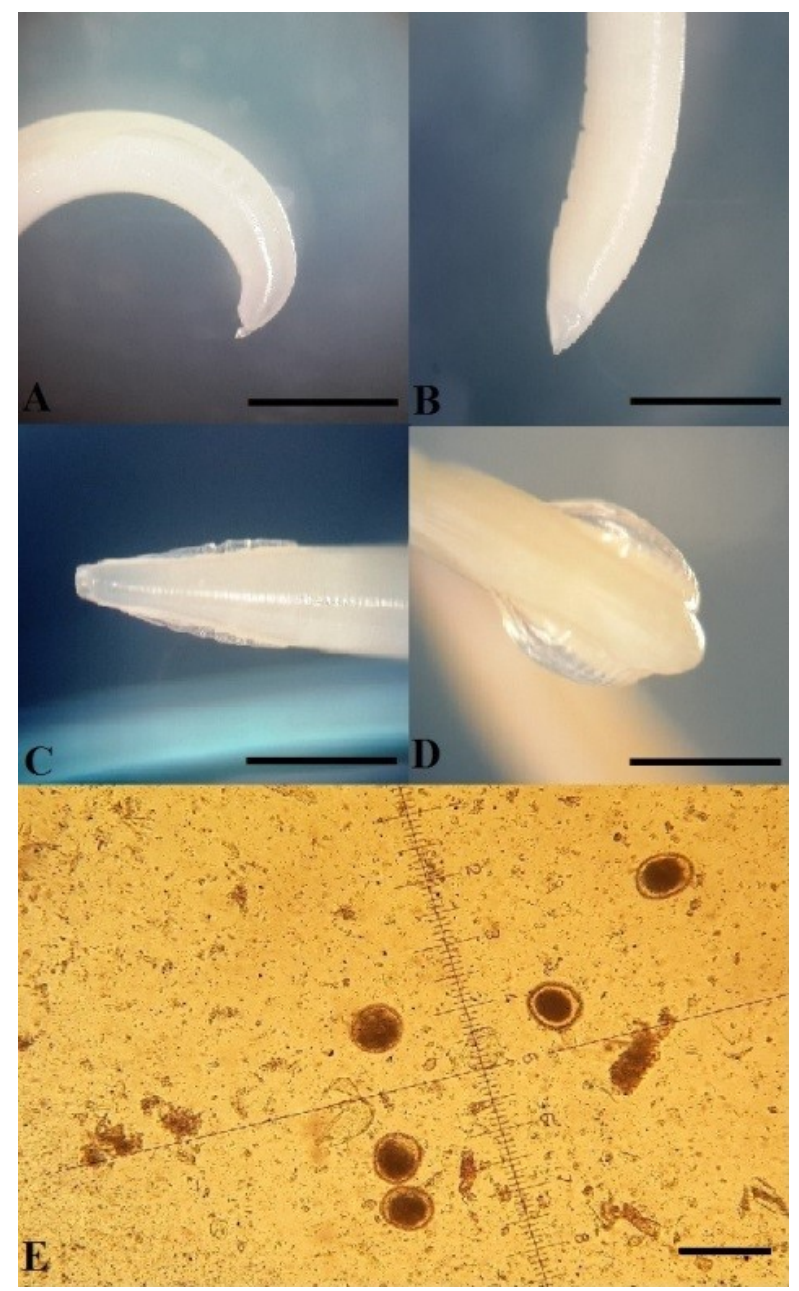

Fig. 1. A - the tail-end of Toxocara canis male, B - the tail-end of Toxocara canis female, $\mathrm{C}-$ the cephalic alae of T. canis, D - the cephalic alae of T. cati, E - eggs of Toxocara canis. A, B, C, D bars indicate $1,000 \mu \mathrm{m}$. E - bars indicate $100 \mu \mathrm{m}$ 
PCR products of about 400 bp were obtained for 17 samples identified as $T$. canis by microscopy and for 3 samples identified as T. cati (Fig. 2). Sequencing and alignment of obtained sequences revealed two groups: six identical sequences displaying $100 \%$ similarity with a $T$. canis sequence from dogs from Egypt (MG214150) and three identical sequences displaying $100 \%$ similarity with a $T$. cati sequence from a cat from Guangdong, China (KY003086). The Toxocara canis ITS-2 and Toxocara cati sequences obtained were deposited in the GenBank database under accession numbers MH044068-MH044073 and MH043956MH043958, respectively.

The phylogenetic tree was reconstructed for the five Toxocara species (Fig. 3). It can be clearly observed that the T. canis and T. cati isolates clustered with the respective reference strains of $T$. canis and

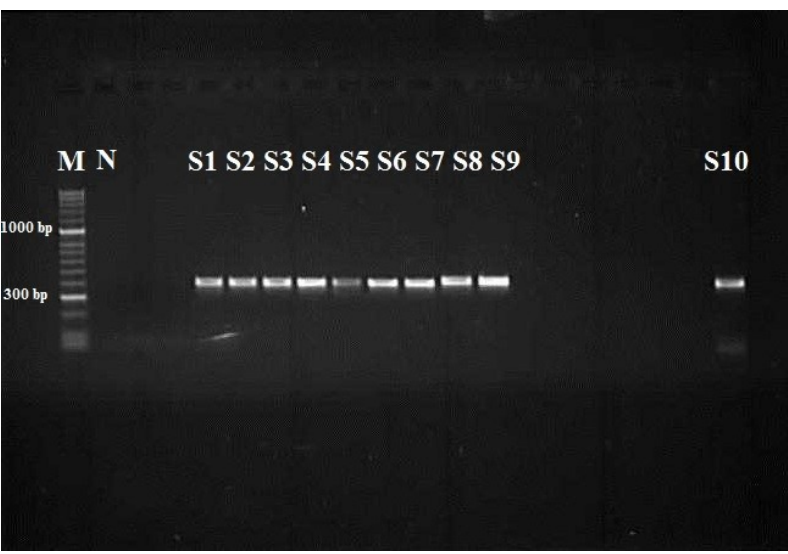

Fig. 2. PCR amplification of ITS-2 ( $400 \mathrm{bp})$ of Toxocara genes on $1.5 \%$ agarose gel. $\mathrm{M}-50$ bp DNA marker, $\mathrm{N}$ - negative control. Samples from 1 to 7 represent Toxocara canis; samples from 8 to 10 represent Toxocara cati T. cati.

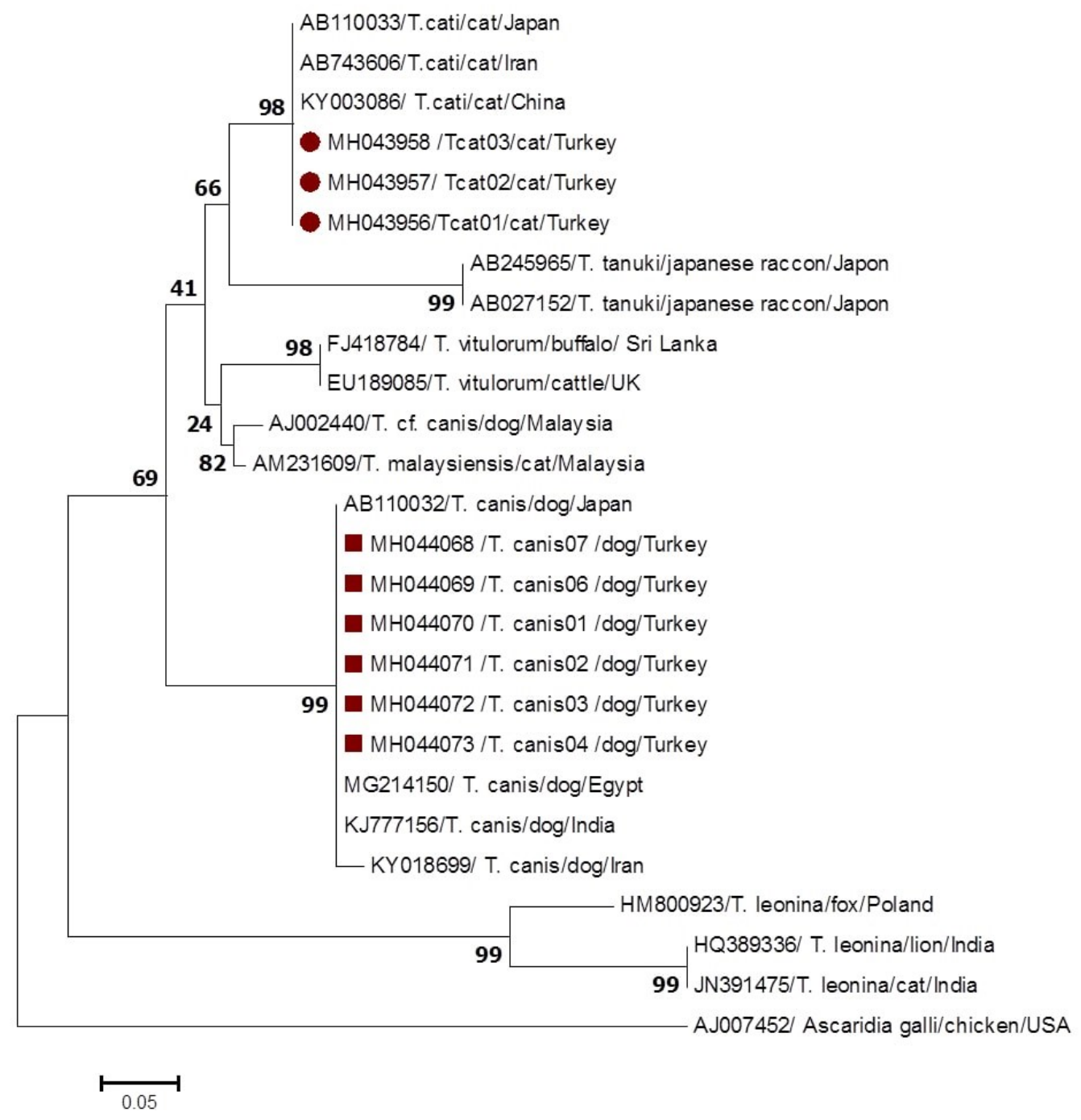

Fig. 3. Neighbour-joining phylogenetic tree (1,000 bootstraps) based on the ITS-2 sequence of ribosomal DNA of T. canis and T. cati isolated from cats and dogs (marked brown) and other sequences of ascarid retrieved from GenBank. The sequence of Ascaridia galli ITS-2 was used as the out-group 


\section{Discussion}

In previous studies, DNA-based approaches have been applied to identify the nematode species, particularly using ITS fragments (rDNA) $(3,8,14,15$, $21,27)$. The ITS sequences obtained from the present study were compared with those published in GenBank, and the results indicated that the ITS2 sequence of ascarids from dogs was identical to that of $T$. canis published previously $(3,11,21)$. The ITS sequence of ascarids from cats was identical to that of $T$. cati (accession numbers KY003086 and AB743606) in GenBank. T. cati, T. canis, and other members of ascarida formed the basis for the reconstruction of the phylogenetic tree, from which $T$. cati was found to be in the same cluster as the isolates reported from China, Iran, and Japan. The results showed that the roundworm from dogs represented $T$. canis belonging to the Toxocara genus. The PCR method is a precise and sensitive method for the detection of ascarid infections in live animals and is based on the principle of detection of DNA originating from the eggs and cells of the parasite. Using ITS-2 sequences as a genetic marker for the PCR approach established in the present study provides positive distinction of $T$. cati from $T$. canis.

Toxocariasis in human is one of the most common helminth infections in the world. The risk of infection in poor people is high (7). The identification and differentiation of $T$. cati and T. canis in the past was based on morphological characteristics (17), a not completely satisfactory method because of the difficulties in identifying and discriminating $T$. cati, $T$. loenina, and $T$. canis by morphology, particularly at egg stages. T. canis and T. cati eggs cannot be distinguished precisely, using microscopic techniques (24). Accordingly, there is a requirement for a molecular approach to detect and accurately identify both ascaridoid nematodes and eggs in the environment.

Having used PCR diagnosis for the Ascarididae family nematodes and different primer pairs targeting various genes for discrimination of the species, He et al. (6) reported that coxl gene sequencing is enough to accurately distinguish and identify $T$. cati. Similarly, in a study performed in Iran on the ascaridoid nematodes, Mikaeli et al. (18) noted that mitochondrial gene sequences could be used confidently for the identification of the parasite. In another study, Pawar et al. (21) used a DNA-based method to amplify ITS-2, a more appropriate and valid gene region to differentiate Toxascaris leonina and Toxocara cati from each other. Various mitochondrial and nuclear genes have been efficiently applied in previous studies in the differentiation of other ascarid species. To illustrate, Luo et al. (16) investigated genetic characterisation of three mitochondrial genes cox1, cox2, and nad1 in their isolates and confirmed that all the parasites belonged to Ascaris suum. In a study on the identification of the characteristics of the ITS gene in A. suum using PCR, the sequence homology was $98.4 \%-99.9 \%$, which is identical with pig isolates reported previously (13). In the present study, the ribosomal ITS-2 gene region was also the clear optimal choice to identify and distinguish the two nematodes accurately. In addition, the ITS-2 sequences showed close resemblance with other $T$. canis and $T$. cati in different parts of the world. The ITS2 rDNA gene should be considered to have a high degree of specificity.

The highly species-specific PCR test for T. canis and $T$. cati detailed here should enable more accurate diagnosis than the detection of the worms by microscopy. This study is also the first demonstration of the existence of adult ascaridoid nematodes in cats and dogs in Turkey by the genetic approach using ITS-2 rDNA as a genetic marker.

Conflict of Interests Statement: The authors declare that there is no conflict of interests regarding the publication of this article.

Financial Disclosure Statement: This study was funded by the authors. The resources (materials, reagents) were financed from the authors' own funds.

Animal Rights Statement: None required.

\section{References}

1. Balkaya I., Avcioglu H.: Gastro-intestinal helminths detected by coprological examination in stray dogs in the Erzurum province Turkey. Kafkas Univ Vet Fak Derg 2011, 17, 43-46.

2. Fisher M.: Toxocara cati: an underestimated zoonotic agent. Trends Parasitol 2003, 19, 167-170.

3. Fogt-Wyrwas R., Mizgajska-Wiktor H., Pacon J., Jarosz W.: Intraspecific variation between the ITS sequences of Toxocara canis, Toxocara cati, and Toxascaris leonina from different host species in south-western Poland. J Helminthol 2013, 87, $432-442$.

4. Gibbons L.M., Jacobs D.E., Sani R.A.: Toxocara malaysiensis n.sp. (Nematoda: Ascaridoidea) from the domestic cat (Felis catus Linnaeus, 1758). J Parasitol 2001, 87, 660-665.

5. Glickman L.T., Schantz P.M.: Epidemiology and pathogenesis of zoonotic toxocariasis. Epidemiol Rev 1981, 3, 230-250.

6. He X., Lv M.N., Liu G.H., Lin R.Q.: Genetic analysis of Toxocara cati (Nematoda: Ascarididae) from Guangdong province, subtropical China. Mitochondrial DNA A DNA Mapp Seq Anal 2017, 31, 1-4.

7. Hotez P.J., Wilkins P.P.: Toxocariasis: America's most common neglected infection of poverty and a helminthiasis of global importance? PLoS Negl Trop Dis 2009, 3, e400.

8. Jacobs D.E., Zhu X., Gasser R.B., Chilton N.B.: PCR-based methods for identification of potentially zoonotic ascaridoid parasites of the dog, fox, and cat. Acta Tropica 1997, 68, 191-200.

9. Jin Y., Shen C., Huh S., Sohn W.M., Choi M.H., Hong S.T.: Serodiagnosis of toxocariasis by ELISA using crude antigen of Toxocara canis larvae. Korean J Parasitol 2013, 51, 433-439.

10. Joy A.T., Chris O.I., Godwin N.C.: Toxocariasis and Public Health: An Epidemiological Review. Glob J Infect Dis Clin Res 2017, 3, 28-39. 
11. Khademvatan S., Rahim F., Tavalla M., Abdizadeh R., Hashemitabar M.: PCR-based molecular characterization of Toxocara spp. using feces of stray cats: A study from southwest Iran. Plos One 2013, 8, e65293.

12. Kumar S., Stecher G., Tamura K.: Mega7: molecular evolutionary genetics analysis version 7.0 for bigger data sets. Mol Biol Evol 2016, 33, 1870-1874.

13. Li K., Luo H.Q., Zhang H., Mehmood K., Shahzad M., Zhang L.H., Li J.K.: Analysis of the internal transcribed spacer region of Ascaris suum and Ascaris lumbricoides derived from free range Tibetan pigs. Mitochondrial DNA Part A 2017, 21, $1-5$.

14. Li M., Lin R., Chen H., Sani R.A., Song H.Q., Zhu X.Q.: PCR tools for the verification of the specific identity of ascaridoid nematodes from dogs and cats. Mol Cell Probes 2007, 21, 349-354.

15. Li M.W., Zhu X.Q., Gasser R.B., Lin R.Q., Sani R.A., Lun Z.R., Jacobs D.E.: The occurrence of Toxocara malaysiensis in cats in China, confirmed by sequence-based analyses of ribosomal DNA. J Parasitol Res 2006, 99, 554-557.

16. Luo H.Q., Zhang H., Li K., Lan Y.F., Shahzad M., Wang X.Q., Khalid M., Mujeeb R., Huang S.C., Li J.K., Yangzom Q.B.: Molecular characterization of ascaris from Tibetan pigs by three mitochondrial markers of nad1, cox1, and cox2. Trop Biomed 2017, 34, 576-582.

17. Matoff K., Wassileff I.: On the biology of Toxascaris leonine (Ueber die Biologie von Toxascaris leonine). Z Parasitenkd 1958, 18, 271-291.

18. Mikaeili F., Mirhendi H., Mohebali M., Hosseini M., Sharbatkhori M., Zarei Z., Kia E.B.: Sequence variation in mitochondrial cox 1 and nad 1 genes of ascaridoid nematodes in cats and dogs from Iran. J Helminthol 2015, 89, 496-501.
19. Moreira G.M., Telmo P.L., Mendonça M., Moreira A.N., McBride A.J., Scaini C.J., Conceição F.R.: Human toxocariasis: current advances in diagnostics, treatment, and interventions. Trends Parasitol 2014, 30, 456-464

20. Overgaauw P.A., Van Knapen F.: Veterinary and public health aspects of Toxocara spp. Vet Parasitol 2013, 193, 398-403.

21. Pawar R.M., Lakshmikantan U., Hasan S., Poornachandar A., Shivaji S.: Detection and molecular characterization of ascarid nematode infection (Toxascaris leonina and Toxocara cati) in captive Asiatic lions (Panthera leo persica). Acta Parasitol 2012, 57, 67-73.

22. Pinelli E., Herremans T., Harms M.G., Hoek D., Kortbeek L.M.: Toxocara and Ascaris seropositivity among patients suspected of visceral and ocular larva migrans in the Netherlands: trends from 1998 to 2009. Eur J Clin Microbiol Infect Dis 2011, 30, 873-879.

23. Soulsby E.J.L.: Helminths, arthropods, and protozoa of domesticated animals. Bailliere Tindall, London, 1992.

24. Uga S., Matsuo J., Kimura D., Rai S.K., Koshino Y., Igarashi K.: Differentiation of Toxocara canis and T. cati eggs by light and scanning electron microscopy. Vet Parasitol 2000, 92, 287-294.

25. Van Knapen F., Buijs J., Kortbeek L.M., Ljungström I.: Larva migrans syndrome: Toxocara, Ascaris, or both? Lancet 1992, 340, 550-551.

26. Yaman M., Ayaz E., Gul A., Muz M.N.: Investigation of helminth infections of cats and dogs in the Hatay province. Turkiye Parazitol Derg 2006, 30, 200-204.

27. Zhu X.Q., Jacobs D.E., Chilton N.B., Sani R.A., Cheng N.A., Gasser, R.B.: Molecular characterization of a Toxocara variant from cats in Kuala Lumpur, Malaysia. Parasitology 1998, 117, $155-164$ 